University of Nebraska - Lincoln

DigitalCommons@University of Nebraska - Lincoln

Faculty Publications: Department of Teaching, Department of Teaching, Learning and Teacher Learning and Teacher Education

Education

$2-2008$

\title{
University Students' Conceptualization and Interpretation of Topographic Maps
}

\author{
Douglas Clark \\ Arizona State University, dbc@asu.edu \\ Stephen Reynolds \\ Arizona State University, sreynolds@asu.edu \\ Vivian Lemanowski \\ Arizona State University \\ Thomas Stiles \\ Arizona State University \\ Senay Yaşar-Purzer \\ Arizona State University, spurzer@purdue.edu \\ See next page for additional authors
}

Follow this and additional works at: https://digitalcommons.unl.edu/teachlearnfacpub

Part of the Teacher Education and Professional Development Commons

Clark, Douglas; Reynolds, Stephen; Lemanowski, Vivian; Stiles, Thomas; Yaşar-Purzer, Senay; Proctor, Sian; Lewis, Elizabeth B.; Stromfors, Charlotte; and Corkins, James, "University Students' Conceptualization and Interpretation of Topographic Maps" (2008). Faculty Publications: Department of Teaching, Learning and Teacher Education. 123.

https://digitalcommons.unl.edu/teachlearnfacpub/123

This Article is brought to you for free and open access by the Department of Teaching, Learning and Teacher Education at DigitalCommons@University of Nebraska - Lincoln. It has been accepted for inclusion in Faculty Publications: Department of Teaching, Learning and Teacher Education by an authorized administrator of DigitalCommons@University of Nebraska - Lincoln. 


\section{Authors}

Douglas Clark, Stephen Reynolds, Vivian Lemanowski, Thomas Stiles, Senay Yaşar-Purzer, Sian Proctor, Elizabeth B. Lewis, Charlotte Stromfors, and James Corkins 


\title{
University Students' Conceptualization and Interpretation of Topographic Maps
}

\author{
Douglas Clark, ${ }^{1}$ Stephen Reynolds, ${ }^{1}$ Vivian Lemanowski, ${ }^{1}$ \\ Thomas Stiles, ${ }^{1}$ Senay Yasar, ${ }^{1}$ Sian Proctor, ${ }^{2}$ Elizabeth Lewis, ${ }^{1}$ \\ Charlotte Stromfors, ${ }^{1}$ and James Corkins ${ }^{1}$ \\ 1. Arizona State University \\ 2. Maricopa Community College
}

Corresponding author - D. Clark, College of Education, Division of Curriculum and Instruction, Arizona State University, Payne Hall, PO Box 870911, Tempe AZ 85287-0911, USA; email dbc@asu.edu

\begin{abstract}
This study investigates the strategies and assumptions that college students entering an introductory physical geology laboratory use to interpret topographic maps, and follows the progress of the students during the laboratory to analyze changes in those strategies and assumptions. To elicit students' strategies and assumptions, we created and refined a topographic visualization test that was administered before and after instruction to 26 students during the first semester of the study and to 92 students during the second semester. To more deeply understand how students think about and conceptualize topographic maps, we focused on eight individual students who were interviewed about their pretest and posttest answers as well as videotaped during three laboratory sessions. We found that even students who claim never to have worked with topographic maps often perform impressively on their pretests by making useful assumptions about symbolic topographic information. Some students, however, begin with less productive assumptions that may be unfamiliar to some instructors (e.g., thinking that the spacing of contour lines indicates elevation instead of slope). Initial success should not be misinterpreted, however, as an integrated understanding of topographic maps. Only in posttest interviews do most students express explanations integrating multiple normative assumptions. In addition to highlighting the strategies and assumptions that college students use to interpret topographic maps, we outline the implications of these findings for the design of learning objectives, curricular activities, and assessments for topographic lessons in introductory college geology courses and the training of future geoscientists.
\end{abstract}

\section{Introduction}

Most college introductory physical geology laboratory courses include a focus on topographic maps. Topographic maps figure centrally in the work of geologists and 
potentially in the lives of many other people including other scientists, hikers, homeowners, business people, engineers, surveyors, and public-service providers. Topographic maps provide significant challenges for students because they require them to visualize contours and elevation numbers as the shapes, slopes, elevations, and locations of landforms. Only by understanding students' topographic abilities, assumptions, schemas, and strategies can we create curricula to better serve their needs and abilities.

This study addresses two questions: (1) What strategies, schemas, and assumptions do students entering an introductory physical geology laboratory demonstrate in their interpretation of topographic maps, and (2) How do these strategies, schemas, and assumptions evolve over the course of instruction? To answer these questions, we analyze pretest and posttest data for 26 students during one semester and 92 students taking refined versions of the test during the following semester. For further insight into their cognitive processes, we focused on eight students who were interviewed about their pretest and posttest answers as well as videotaped during three laboratory sessions. The results of these analyses suggest that even students who claim never to have worked with topographic maps often perform impressively on their pretests by making useful assumptions about symbolic topographic information. These same students encounter a number of challenges, however, which we might better address through augmented curricula.

\section{Background}

\section{Cognitive Demands in Processing Topographic Maps}

Interpreting topographic maps poses significant cognitive challenges for students in terms of: (a) the minimal structuring of information flow, (b) the domain-specific concepts and symbol systems, and (c) the visual-spatial challenges of interpreting threedimensional (3D) information from two-dimensional (2D) representations (Gobert, 2005). While many verbal and textual information sources organize information flow through the structure of the text or dialog, topographic maps present their information simultaneously without linear structure (Larkin \& Simon, 1987). In terms of symbol systems, as Gobert (2005) explains, topographic maps are semantically-rich representations that involve complex domain-specific concepts and symbol systems (as distinguished from iconic visual representations, such as traffic signs, which do not require a deep domain-specific knowledge base). Interpreting and reasoning with semantically-rich visualizations is therefore much more complex (Gobert, 1994). Adding to this complexity, interpreting 3D topographic information from 2D representations requires the coordination of complex spatial skills with domain-specific knowledge (Eley, 1981; Lanca, 1998; Schofield \& Kirby, 1994).

Geologists often engage in tasks that involve processing the visual-spatial information embedded within maps. They also interpret features at field study sites and transcribe this understanding to topographic maps. These tasks require the use of visualization to create mental representations of the implied landscapes. Research by 
Student Conceptualization and Interpretation of Topographic Maps 377 Rieber (1995) and others indicate that a subject's background knowledge interacts with the visual stimuli to create these mental representations. "Interpretation and understanding are continually filtered through one's entire knowledge, values, and beliefs. People often see and imagine what they want to see and imagine. Visualization, like any cognitive process, is greatly influenced by prior knowledge" (Rieber, 1995, p. 53).

Creating these mental representations of topographic information involves spatial orientation and visualization, both of which present significant challenges for novice map-readers (Eley, 1987, 1988). Students may be able to visualize simple landscape features, but struggle when it comes to manipulating images in complex ways, such as viewing mapped surfaces from particular perspectives or comparing features acquired from oblique images to a topographic map of the same landscape. Ishikawa and Kastens (2005) describe spatial thinking as:

(a) recognizing, observing, recording, describing, classifying, remembering, and communicating the two- or three-dimensional shapes, structures, orientations, and positions of objects, properties, or processes; (b) mentally manipulating those shapes, structures, orientations, and positions by rotation, translation, deformation, or partial removal; (c) making interpretations about why the objects, properties, or processes have those particular shapes, structures, orientations, and positions; (d) making predictions about the consequences or implications of the observed shapes, structures, orientations, and positions; and (e) using spatial thinking as a shortcut or metaphor to think about the distribution of processes or properties across some dimension other than length-space. (pp. 184-186)

In addition to spatial coding, map readers may support their spatial thinking through verbal coding as well (Kinnear \& Wood, 1987; Schofield \& Kirby, 1994). For instance, a model may be remembered as an image and/or as a verbal construct that preserves size, distance, and other relational kinds of information (e.g., "a small hill one mile to the northwest of where the river bends to the east").

Eley $(1981,1987,1988,1993)$ found that map readers generate mental representations that are specific in perspective rather than universal or general in form. Eley (1991) also demonstrated that map users selectively encode features from the map in task-determined fashion. Together, these findings suggest an imagery model of mental representation, as opposed to a non-imagery model that might depend solely on descriptive information. These mental representations also appear to involve collections of related elements rather than contiguous or holistic entities. In other words, map readers seem to detect specific surface features, such as hills and valleys, and arrange these features in spatially appropriate ways (Eley, 1993). In sum, students' mental representations of topographic maps seem to involve images organized from specific perspectives composed of multiple elements coordinated by spatial representations as well as some verbal information.

It is believed that learners focus on spatial regions by partitioning the contour map into subparts. Shelton and McNamara (2001) proposed a theoretical framework in which learning the spatial structure of a new environment involved interpreting the layout in terms of a spatial reference system. This was followed by Mou 
and McNamara's (2002) claim that the reference system is defined by the layout of the environment, and that axes intrinsic to the layout are selected and used to represent locations of objects. The chosen axes are dependent upon the spatial and non-spatial properties of the objects, cues in the surrounding environment, and instruction. Directions in the environment are often created by assigning a conceptual "north" to the layout and, as a result, the directions determine how the space is interpreted, and hence how it is mentally represented (Shelton \& McNamara, 2001). Reference frames enable the mapping of spatial-linguistic expressions onto objects, and the type of reference frame is generally defined by the orientation source (Carlson, 1999). Origin, scale, direction, and orientation are all reference frame parameters but are not all necessary when defining a spatial relation (Logan \& Sadler, 1996). Just and Carpenter (1985) studied the relationship between coordinate-system strategies and performance on spatial-ability tests, and found that coordinate strategies had an effect on object recognition, information retrieval, and spatial transformations.

Research on visual search theories with regard to maps provides further valuable insights into the processes of feature integration, attention engagement, and guided search (Lloyd, 1997). Feature integration (Treisman, 1991) suggests that students may process information for several characteristics, such as physical properties (e.g., color, texture, and shape) and spatial properties (e.g., location, size, and orientation). Attention-engagement theory (Duncan \& Humphreys, 1992) suggests that when students search for a feature, significant complications arise when similar, yet different, targets are encountered. From the perspective of guided-search theory (Cave \& Wolfe, 1990), when a target shares a common characteristic with another, but does not match it exactly, this object will not induce a "pop out" effect. When no "pop out" occurs, the map-reader depends on both bottom-up and top-down search methods. Top-down search methods depend, as discussed above, on the map reader's holistic knowledge of the target. On the other hand, the discrete information given on the map is referred to as bottom-up information. Lloyd (1997) found that when target symbols with unique features are sought, the target "pops out" of the map independent of the number of symbols on the map.

\section{Students' Abilities and Processing Strategies}

Research has generally focused more on students' ability to interpret topographic maps and less on the specific strategies that students use to interpret the maps (e.g., Boardman, 1989; Carter, Patrick, Wiebe, Park, \& Butler, 2005; Ghuman \& Davis, 1981). For example, Carter et al. (2005) found that middle school students have difficulty in switching between $2 \mathrm{D}$ and $3 \mathrm{D}$ representations and in constructing the relationship between 2D and 3D representations. At the secondary level, students are often only briefly exposed to concepts such as contour lines and relief. Boardman's (1989) investigation of students' ability to interpret topographic maps revealed that some students were: (1) confused by the absence of a number on a contour line, (2) did not know how to interpret the space before and after a numbered line, (3) did not understand the relationship between slope and closeness of contour lines, and 
(4) confused high numbers on contour lines with steepness. Although both 9thgrade and 11th-grade students had difficulty with these items, the concept of contours appears to be more difficult for younger students. Ghuman and Davis (1981) found that although students' age correlated with basic map reading skills, including 2D orientation, age did not show the same strong connection to skill in comparing 3D images. They also found that the easiest task for most students aged 9-16 years was identifying the details of $2 \mathrm{D}$ shapes on maps, but that finding compass directions, using six-figure grid references, measuring horizontal distances, and measuring vertical distances were not generally well understood, regardless of intelligence and age. Ghuman and Davis noted that horizontal and vertical (contour) distance were the most difficult of these four skills.

In terms of research relating more directly to students' strategies for interpreting topographic maps, Lanca (1998) studied the ability of participants to create 3D crosssectional representations of topographic maps, and found no significant difference between male and female participants concerning their ability to solve cross-section problems. She found evidence, however, that males created 3D representations of topographic maps as part of their spatial processes, while females did not. She also found that spatial processing strategies may be more efficient than other forms of processing, such as verbal, for tasks involving memory. Lanca suggested that further research was needed to investigate the specific strategies used to learn topographic maps.

Schofield and Kirby (1994) found that untrained subjects had no coherent strategy and attempted to encode topographic map information using inefficient spatial processes. They concluded that spatial process strategies are inherent to the way subjects approach a map-location task. However, the specific spatial strategies used by the subjects, and the effectiveness of these strategies, were not investigated. Subjects with no apparent strategy, yet high visual learning preference, still performed well on map-location tasks. Schofield and Kirby concluded that these findings may result from a bundling of spatial strategies within the visual-learning preference and that further investigation was needed.

\section{Experts' Behavior and Processing Strategies}

Expert topographic map reading is thought to begin with the decomposition of symbolic information, from coarser to finer details, and then proceeds through an opposite process of global processing (Eastman, 1985). This process of breaking down incoming information and then mentally reconstructing the pieces into a meaningful whole has been termed "analysis-by-synthesis" (Neisser, 1967). Interpreting and using topographic maps for complex tasks thus depends on "bottomup" as well as "top-down" forms of cognitive processing. Top-down approaches are typically associated with experts of a given field. In chess, for example, topdown processing enables expert players to recognize patterns using repertoires of stored schema-like chunks of information (Chase \& Simon, 1973; de Groot, 1978). This chunking behavior has also been observed in experts' interpretation of topographical maps (Chang, Lenzen, \& Antes, 1985; Gilhooly, Wood, Kinnear, \& Green, 
1988). Over time, as Gobert (2005) explains, experts develop domain-specific skills for interpreting visual information referred to as schemata (Brewer \& Nakamura, 1984; Rumelhart \& Norman, 1975; Schank \& Abelson, 1977), which provide perceptual and cognitive structures to direct, organize, and control the flow of information that the expert processes in pursuit of specific goals. Gilhooly et al. (1988) found, for example, that expert students used "specialist schemata" (e.g., interlocking spurs and other high-level geological descriptors) to make sense of topographic maps whereas low-skill students used only "lay schemata" of simple features such as hills, rivers, and valleys. Related to these findings, Eley (1993) demonstrated that the mental processes of practiced map users are both strategic and flexible. The practiced map user selects contour features that lead to a simplified mental representation of the landscape.

According to Lowe (1993), two types of background knowledge-domain-general knowledge and domain-specific knowledge-play major roles in the construction of appropriate mental representations. Domain-general knowledge is possessed by the general population and is applicable in a variety of visually simulated situations. Domain-specific knowledge is based on the individual's experience with the domain matter and enables a person to access the deeper scientific meaning depicted in maps, diagrams, and other visuals. To determine the mental processes that take place in the early stages of constructing a mental representation, Lowe distinguishes between perceptual and semantic classification strategies for interpreting contoured weather maps. Perceptual classification strategies are used by domaingeneral subjects to describe features of a map in generic terms, such as shape or position. In contrast, subjects with domain-specific knowledge engage in semantic classification processes to develop functional and associative patterns between presented features on the map and their underlying meaning. Lowe studied the mental representations and processing capabilities of novices and experts in the field of meteorology. He found that skilled subjects used semantic-classification processes triggered by their domain-specific knowledge, whereas non-skilled subjects relied on perceptual classification strategies. As a result, instruction involving visualization may not fulfill its purpose if there are constraints related to background knowledge or information-processing strategies that limit the way subjects perceive or use the visuals. Lowe (1993, p. 158) stated, "For an explanatory scientific diagram to be an effective instructional resource, the assumption is that the student will be able to build a meaningful and appropriate mental representation of the scientific system it portrays." As visuals become more abstract, it may be difficult for novices to develop the mental models they need to interpret them. Lowe speculated that the lack of an appropriate mental representation causes problems with the mental processes necessary for conceptual recall and problem solving. As subjects gain experience in the domain, their ability to create appropriate mental models increases. Gilhooly et al. (1988) demonstrated that skilled map readers use their domain-specific knowledge to encode and better remember information. The more experienced or skilled the subjects are, the better they are at retrieving large chunks of information. Helping subjects create mental models that represent the scientific or techni- 
cal systems illustrated in the visuals is a beneficial process (Mayer \& Gallini, 1990), and prior knowledge plays an important role in this process.

\section{Goals for the Current Study}

Clearly, students' conceptualization and visualization of topographic maps involves a complex interaction of skills, abilities, and understanding. The purpose of this study is to assess the strategies and assumptions that college students bring to an introductory physical geology laboratory regarding topographic maps. Specifically, this study addresses two questions: (1) What strategies, schemas, and assumptions do students entering an introductory geology laboratory demonstrate in their interpretation of topographic maps, and (2) How do these strategies, schemas, and assumptions evolve over the course of instruction?

\section{Methodology}

We conducted our investigation of students' topographic strategies, schemas, and assumptions at a large ethnically diverse public university in the southwestern United States. This study took place in an introductory geology laboratory class. The laboratory sections studied are typical of the other introductory geology laboratory sections offered by the department, considered neither "honors" nor "remedial," and all sections use a common syllabus and activities. The laboratory was designed for freshman and does not require simultaneous enrollment in the introductory lecture class. Although the class was designed for freshman students, many upperclassmen take the laboratory to fulfill a required science elective. During the laboratory, students work in groups, of their own choosing, on the computer-based and traditional geology laboratory activities.

\section{Data Sources: Topographic visualization pretest and posttest data}

Twenty-six students participated in this study during the first semester. All of them took the geo-visualization test before the curriculum began and completed the posttest 5 weeks later following the portion of the curriculum that focused most heavily on topographic maps. Eight of the 26 students, who were selected based on their self-rating of their prior experience with topographic maps, participated in the case studies. The following semester, 92 additional students took revised versions of the geo-visualization pretest and posttest. Almost all of the students from both semesters were non-science majors. An even distribution of males and females participated in all phases of the investigation.

The first version of the topographic visualization pretest and posttest involved 14 questions to reveal students' understanding of topographic maps and their ability to move between $2 \mathrm{D}$ and $3 \mathrm{D}$ representations (see examples in the Results section). During the following semester, 92 additional students completed a refined version of the pretest and posttest involving 30 items. The refinements for the second semester were based on the results from the first semester, but many of the 
questions remained the same or were similar enough to allow comparisons for the purposes of establishing generalizability.

The tests consist of three types of questions that can be categorized into three categories. Transformational tasks involve using symbolic information to achieve complex tasks involving transformations between topographic maps and 3D representations. Identification tasks involve interpretation of symbolic information to identify specific features on a geographic map. Comparison tasks involve interpreting symbolic information to make comparisons across a topographic map. Content validity of the questions was established by field geologists from the department.

The initial geo-visualization test included 14 questions. It had a K-R 20 reliability of .52 due to the small sample size and the small number of items in the test. The revised version included 30 items and had a K-R 20 reliability of .80 . The revised version was based on the insights we gathered from our case study interviews and the item analysis on student's responses to pretests and posttests. We created new items for the test and modified some of the initial items. After these refinements, the new version of the test was created and administered to a new group of 92 students.

\section{Data Sources: Self-rating of topographic map experience}

The first-semester students rated themselves on their ability to read topographic maps both before and after the instructional sequence. On the pretest, three students self-rated their experience and skills with topographic maps as "none," 11 self-rated as "poor," seven self-rated as "fair," and five self-rated as "good." No students rated themselves as "excellent." Given the following options, the subjects indicated the source(s) of their prior experience to include: hiking or other outdoor activity (five students), road atlases with topographic contours (six students), Boy Scouts or Girl Scouts (four students), military (zero students), previous college class (eight student), K-12 class (12 students), other (zero students), and none of the above (one students). Subjects were also asked to describe their training and experience with topographic maps in greater detail. Two subjects stated experience with topographic maps through a college-level geography course. The majority of students reported that an Earth science and/or geography class in middle school and/ or high school was the primary source of their knowledge about topographic maps. Many students indicated that they "didn't remember much" even if they had been exposed to the material.

\section{Data Sources: Case-study students}

During the first semester, eight of the 26 students were selected on the first day of class to participate in case studies based on their self-reported experience and ability with topographic maps. The eight case-study students were chosen to represent the range of experience reported by the class. Of the eight case-study students chosen, one student self-rated his experience and skills with topographic maps as "none," three self-rated as "poor," two self-rated as "fair," two self-rated as "good." No stu- 
dents rated themselves as "excellent." The case-study group did not include any students with prior college experiences.

The eight case-study students were interviewed about their answers in the pretest and posttest and their reactions to the curriculum. The remaining 18 students from the first semester clarified their posttest answers and reactions to the curriculum in written form. The eight case-study students were interviewed specifically about their understanding and thinking regarding seven key questions. The interviews were analyzed to determine the assumptions, schemas, and strategies that students used to address these questions. The eight students were also videotaped during the three laboratory sessions that focus on topographic maps to observe the students' interactions with the curriculum and each other.

A battery of interview questions for all interviewers was determined prior to the interviews focusing on specific questions on the tests. The interview questions focused on elucidating how the students had arrived at their answers and interpretations. Only content-neutral prompts were allowed, such as: "Can you tell me how you went about deciding on your answer?," "What do you mean by ...," and "How do you know that answer is correct?" After the interviews, we transcribed the data and shared it with the other interviewers. Individual researchers first identified strategies and assumptions displayed by the case-study students. Disagreements between individual researchers regarding the interpretation of a transcript segment were then resolved through group discussion and consensus.

\section{Course Curriculum}

The curriculum in the geology laboratory course emphasizes the core skills of topographic and geologic map reading, rock and mineral identification, recognition of geologic structures, determining sequences of geologic events, and understanding the implications of geology to society. Instruction during the first half of the semester is situated in a virtual world called "Painted Canyon." During this half of the semester, all curricula about maps, minerals, rocks, and relative dating takes place in the context of this simulated world. Students work in pairs to develop an integrated understanding of the geology of Painted Canyon. The curriculum includes hand specimens, manipulable 3D computer images, paper maps, and computerized maps. Topographic maps and the concept of contour line interpretation are addressed first via the familiar volcano-in-a-box exercise and the Visualizing Topography website: http://reynolds.asu.edu/topo gallery. The website features interactive QuickTime Virtual Reality animations of contour-draped topographic terrains. These animations allow the students to rotate, tilt, progressively cover with water, and slice the terrains to facilitate their investigation of the topography of the terrain.

\section{Results by Test Question Category}

This study analyzes the assumptions, schemas, and strategies that students use to answer questions related to topographic maps within the curriculum. The 14 test ques- 
tions can be categorized into three main groups, including: Identification Questions, Comparison Questions, and Transformation Questions. Table 1 presents descriptions of the questions for each category along with pretest and posttest scores for each question. After summarizing the results for these three categories of questions, we discuss the assumptions, schemas, and strategies identified by analyzing the casestudy student responses for one or more key questions from each category. Table 1 marks these questions with an asterisk. Figures 1-6 present full versions of these key test questions.

\section{Identification Questions}

The identification questions ask students to identify a landscape feature on a topographic map. Generally, an identification question requires students to interpret map symbols using what they already know about landscape features. Students therefore draw upon mental of landscape features and their interpretations of topographic symbols. Mental models of landscape features, which may be visually and verbally coded, assist students in developing identification criteria. Assumptions about topographic symbols determine how students derive and understand spatial information from maps. In this study, undergraduate students are moderately successful in identifying landscape features such as hills, cliffs, and depressions. Additionally, students exhibit improvement in their performance on identification questions through instruction (Table 1).

With a better understanding of topographic symbols, students are more likely to perform better on identification questions. Learning that hachure marks indicate a depression on a closed contour may have allowed more students to identify such a feature correctly in the posttest (\#I2). Realizing that elevation numbers also provide information about slope when combined with contour spacing may have helped more students in selecting maps in the posttest featuring "a cliff with a gentle slope at the bottom" (\#I4) and "a hill surrounded by flatter terrain" (\#I5). Similarly, in the identification question (\#I3) that prompts students to identify an area of close parallel lines (that represent a cliff), many students misidentify the pattern as a valley on the pretest. By the end of instruction, however, more students in the first semester correctly identify the pattern as a cliff. The test question was revised and made more difficult for the second semester, resulting in lower pretest and posttest scores, but the overall pattern shows the same improvement.

Several types of prior knowledge appear to help students on the tests. Most students are successful on the pretest when asked to identify an area of a topographic map representing a round hill (\#I1, Figure 1). Hills are familiar land formations, which can be recognized on topographic maps by their unique pattern of closed, concentric contour lines. After instruction, all first-semester students correctly identify the area as a round hill in the posttest. In an effort to make the question more difficult for the second-semester students, "round" was omitted from the prompt. This resulted in an overall lower percentage of second-semester students being able to identify the area correctly, an indication that text-based criteria play a role in the identification process. 
Table 1. Performance by test question category (first semester, $n=26$; second semester $n=92$ )

\begin{tabular}{|c|c|c|c|c|c|}
\hline & & \multicolumn{2}{|c|}{ First semester } & \multicolumn{2}{|c|}{ Second semester } \\
\hline & & $\begin{array}{r}\text { retest } \\
(\%)\end{array}$ & $\begin{array}{r}\text { Posttest } \\
(\%)\end{array}$ & $\begin{array}{r}\text { Pretest } \\
(\%)\end{array}$ & $\begin{array}{r}\text { Posttest } \\
(\%)\end{array}$ \\
\hline \multicolumn{6}{|c|}{ Identification questions } \\
\hline & Identify an area of a map representing a round hill. & 81 & 100 & 71 & $90^{\mathrm{a}}$ \\
\hline & Identify an area of a map that represents a depression. & 69 & 92 & - & - \\
\hline & Identify an area of a map that represents a cliff. & 65 & 92 & 43 & $79^{\mathrm{b}}$ \\
\hline I4 & $\begin{array}{l}\text { Choose map showing a cliff with a gentle slope at the bottom } \\
\text { from four maps. }\end{array}$ & 73 & 83 & 71 & 77 \\
\hline I5 & $\begin{array}{l}\text { Choose a map representing hill surrounded by flatter terrain } \\
\text { from four maps. }\end{array}$ & 69 & 88 & 74 & - \\
\hline \multicolumn{6}{|c|}{ Comparison questions } \\
\hline & $\begin{array}{l}\text { Choose correct description of elevation changes from } \\
\text { one map point to another. }\end{array}$ & 85 & 100 & 92 & $92^{\mathrm{c}}$ \\
\hline $\mathrm{C} 2 *$ & Locate point on a map with the lowest elevation. & 96 & 96 & 88 & $66^{\mathrm{d}}$ \\
\hline $\mathrm{C}^{*}$ & Locate point on a map with the flattest topography. & 92 & 100 & 90 & - \\
\hline & $\begin{array}{l}\text { Locate point on a map with same elevation as another } \\
\text { designated point. }\end{array}$ & 85 & 88 & - & - \\
\hline C5 & $\begin{array}{l}\text { Choose correct description of elevation changes from } \\
\text { one map point to another. }\end{array}$ & 65 & 92 & - & 42 \\
\hline & $\begin{array}{l}\text { Choose a profile picture that best represents the } \\
\text { topography of a given map. }\end{array}$ & 69 & 88 & 76 & $74^{\mathrm{e}}$ \\
\hline \multicolumn{6}{|c|}{ Transformation questions } \\
\hline & $\begin{array}{l}\text { Rotation of azimuth and perspective to identify a point } \\
\text { from a 3D landscape on a topographic map. }\end{array}$ & 39 & 58 & 20 & $28^{\mathrm{f}}$ \\
\hline $\mathrm{T} 2^{*}$ & Identify 3D landscape from four 3D views. & 31 & 75 & 48 & 45 \\
\hline T3* & Identify 3D landscape from four 3D views. & 50 & 58 & 41 & 46 \\
\hline
\end{tabular}

* Focal questions for the interviews; " - " indicates that directly comparable question was not included for that test during the second semester. The following footnotes describe revisions to that version of that question for that version of the test:

a. We changed "round hill" to "hill" to eliminate providing students with an additional clue.

b. Contour lines in the first-semester pretest/posttest and the second-semester pretest appeared to merge together. The map scale in the second semester posttest was enlarged to better view individual contour lines.

c. The second semester posttest was made more difficult by eliminating three elevation marks around the points students were directed to examine. Students had to compare elevations from another part of the map to answer this item successfully.

d. In the first semester pretest/posttest, the correct answer looked significantly different than the other options; it was the only option with contour lines spread out across a greater area. The second semester question options were made more equitable by revising an incorrect option on top of a flat mesa.

e. An additional distractor was added in the second-semester posttest.

f. A different perspective and a more detailed map were used for the second semester. We also added another distractor in the second semester posttest. 
I1. Using the topographic map to the right, how would you describe the feature within the black box?
a. round hill
b. valley
c. ridge
d. depression

\begin{tabular}{|c|c|c|c|c|}
\hline & $\mathrm{A}^{*}$ & $\mathrm{~B}$ & $\mathrm{C}$ & $\mathrm{D}$ \\
\hline Pretest & 81 & 4 & 15 & 0 \\
\hline Posttest & 100 & 0 & 0 & 0 \\
\hline
\end{tabular}

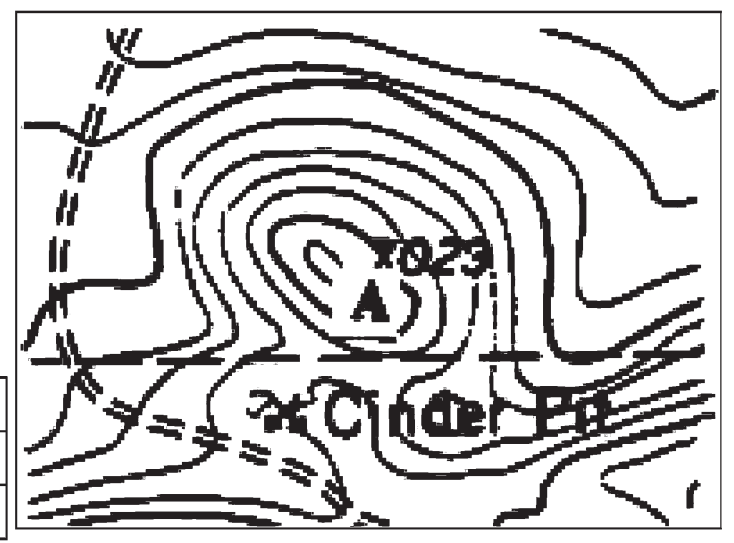

Figure 1. Description of question I1, "Identify a Round Hill” (image is a close-up of the target area of the larger map included for the test question). ${ }^{*}$ Correct answer

\section{Comparison Questions}

Comparison questions require students to interpret map symbols and derive spatial information to compare two or more points on the map. Because the map becomes the main source of information, assumptions about topographic symbols largely determine how students derive and compare spatial information. Students score higher pretest scores for this category of questions than for the identification or transformation question categories. The pretest scores are so surprisingly high that there is not much room for improvement in the posttest, but students do indeed improve (Table $1)$.

Some of the comparison questions require the evaluation of elevation and slope at different points on the map. For example, one comparison question asks students to choose the point on a topographic map with the lowest elevation (\#C2, Figure 2). To successfully answer this question, students must make assumptions about the meaning of contour lines and elevation numbers. Specifically, they must realize that contour line numbers represent elevation above sea level on terrestrial maps and therefore higher numbers are equivalent to higher points on the map. Students must continually use this information to compare different points on the map. This task poses no difficulty for most students, with $96 \%$ of the first-semester students answering this question correctly in both the pretest and posttest.

A similar comparison question asks students to choose the flattest area on the map (\#C3, Figure 3). To answer this comparison question successfully, students need to understand that more closely spaced contour lines indicate steeper slopes. Again, most students perform well. Ninety-six percent of the first-semester class answered correctly in the pretest, while all students answered correctly in the posttest. 
C2. Examine the topographic map. Which letter is placed at the lowest elevation on the map?

\begin{tabular}{|l|c|c|c|c|}
\hline & A & B & C $^{*}$ & D \\
\hline Pretest & 0 & 4 & 96 & 0 \\
\hline Posttest & 0 & 4 & 96 & 0 \\
\hline
\end{tabular}

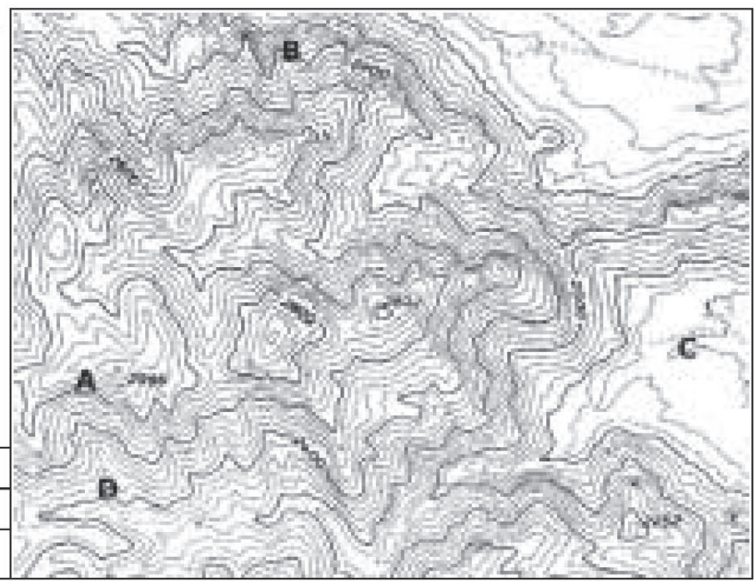

Figure 2. Description of question C2, "Locate Lowest Elevation"

Another comparison question, which is slightly more complex, asks how elevation would change if the student were to move from one designated point to another on a topographic map (\#C1, Figure 4). Successful comparison depends not only on the ability to identify high and low areas on the map but also on the ability to recognize that the variable spacing between contour lines signifies the degree of local slope. On the pretest, most students do well. Eighty-five percent of the first-semester students answer correctly. Even students who rated their ability with topographic maps as poor or none did well on this particular question prior to instruction.

Overall, students are initially quite successful on comparison questions. The high performance of students, many of whom reported "poor" or "no" map reading ability, supports the idea that comparison questions are less complex than the other categories. Tasks requiring students to compare similar types of spatial information across a topographic map may pose less of a challenge than tasks that require students to op-

C3. Examine the topographic map. Which letter is placed in the area with the least slope (flattest topography) on the map?

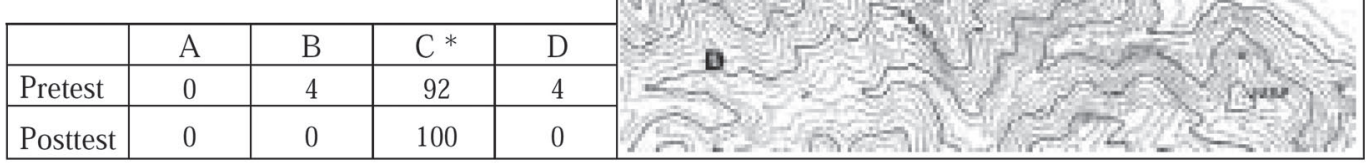

Figure 3. Description of question C3, "Locate Flattest Topography" 
C1. If you were to hike from point $X$ to point $Y$ on the topographic map, then you would be:

a. traveling up in elevation

b. traveling down in elevation

c. staying at the same level

d. none of the above

\begin{tabular}{|l|c|c|c|c|}
\hline & $\mathrm{A}$ & $\mathrm{B}^{*}$ & $\mathrm{C}$ & $\mathrm{D}$ \\
\hline Pretest & 8 & 85 & 8 & 0 \\
\hline Posttest & 0 & 100 & 0 & 0 \\
\hline
\end{tabular}

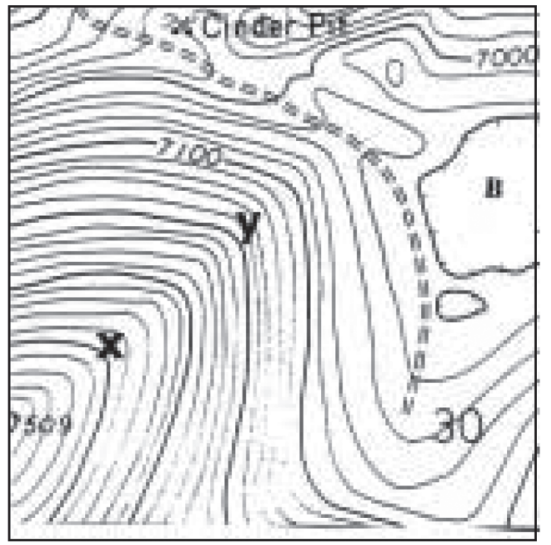

Figure 4. Description of question C1 "Describe Elevation Change" (image is a close-up of the target area of the larger map included for the test question)

erate on spatial information gathered from different sources (e.g., mental models and images). Prompts for comparison questions may also cue fruitful assumptions and logical operations needed for the task.

\section{Transformation Questions}

This type of question asks students to perform complex operations using spatial information derived from topographic representations and land-surface perspectives (shaded 3D drawings of the land surface topography). These questions require students to use multiple strategies and assumptions while interpreting topographic symbols and visualizing map surface features. They demand that students visualize and rotate mental models of land-surface features in order to derive spatial information for comparison. Initially, students are only somewhat successful on this type of question, but they improve their performance with instruction (Table 1).

One transformation question asks students to identify a specific point from a landsurface perspective on a topographic map that is rotated in relation to the land-surface perspective (\#T1, Figure 5). The shaded land-surface perspective is a side view of the landscape. To answer this question correctly, students must rotate a mental representation of the image as well as adjust the side-perspective to a birds-eye perspective of the landscape. This question therefore requires rotation of azimuth and perspective. Less than one-half of the students in the first semester choose the correct answer on the pretest. After instruction, the performance of the class improves. Students in the lower quartile use a "direct mapping" strategy (see discussion of "Assumptions about 3D Transformations" below) that causes one distracter to be selected more frequently than others. Extraneous visual cues thought to encourage direct mapping were identified and corrected for the second-semester test (e.g., framing the topographic representation). Students in the second semester do not perform as well and show minimal improvement after instruction. Interestingly, however, wrong answers become more evenly distributed among distracters in the second-semester posttest. 
T1. Look at the three-dimensional representation of a landscape below (top) and the topographic map (bottom) showing the same area. Remember that the views of the landscape and the topographic map may not be from the same direction. One may be rotated compared to the other. Which point on the topographic map (below) is point $\mathrm{X}$ on the model above?

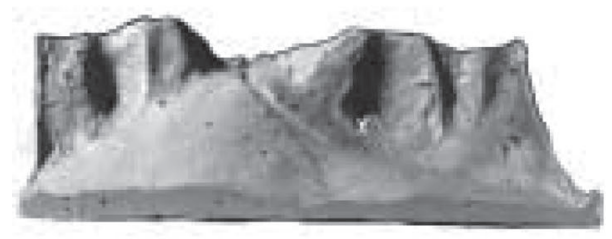

\begin{tabular}{|l|l|l|l|l|}
\hline & A & B $^{*}$ & C & D \\
\hline Pretest & 38 & 38 & 15 & 8 \\
\hline Posttest & 21 & 58 & 21 & 0 \\
\hline
\end{tabular}

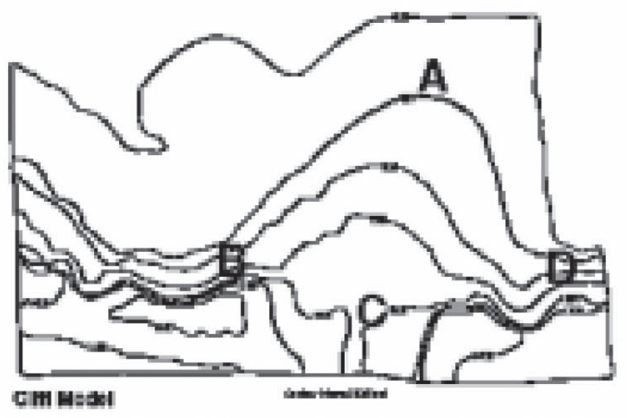

Figure 5. Description of question T1 "Rotation of Azimuth and Perspective." The maps are reduced in size from the test originals

The other transformation questions ask students to visualize a side-view perspective by imagining themselves standing at a point on one side of a topographic map and looking toward a point on the opposite side of the map (\#T2 and \#T3, Figure 6). The students must choose the correct land-surface perspective that represents that view. Question T2 "looks" from the west side of the map, while question T3 "looks" from the east side of the map. For question T2, the first-semester students demonstrate moderate improvements with $31 \%$ of students answering correctly in the pretest and $75 \%$ of students answering correctly in the posttest. The second-semester students, however, show no improvement. For Question T3, both first-semester and second-semester students show only slight improvement.

\section{Student Assumptions, Schemas, and Strategies}

From analyzing student interviews for the selected key questions and from previous experience with piloting the topographic visualization test, we identified several assumptions, schemas, and strategies used by one or more students (Table 2). These can be subdivided into three general topics, including: (1) elevation and slope; (2) shape of contour lines and terrain; and (3) 3D transformations. We further classified the assumptions, schemas, and strategies as: (a) normative (shared by expert geologists); (b) transitional (potentially useful, but not universally normative); or (c) problematic (non-normative and non-productive). In order to provide context for the student examples of these assumptions, Table 3 provides a profile of the case-study students in terms of subject matter tests, spatial scores, and self-assessments. 
T2. Which perspective below is taken looking from location $\mathrm{X}$ across to location $\mathrm{Y}$ on the topographic map?

T3. Which perspective below is looking from the opposite direction (Y looking toward X)?

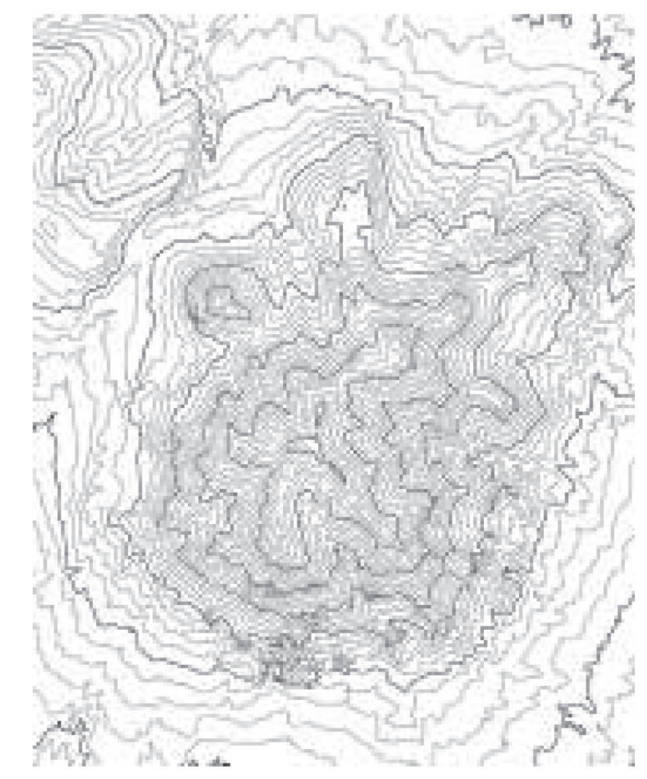

\begin{tabular}{|l|c|c|l|c|}
\hline & A & B & C & D \\
\hline T2 Pretest & 15 & 35 & $31^{*}$ & 19 \\
\hline T2 Posttest & 4 & 17 & $75^{*}$ & 4 \\
\hline T3 Pretest & 19 & 12 & 19 & $50^{*}$ \\
\hline T3 Posttest & 13 & 17 & 13 & $58^{*}$ \\
\hline
\end{tabular}

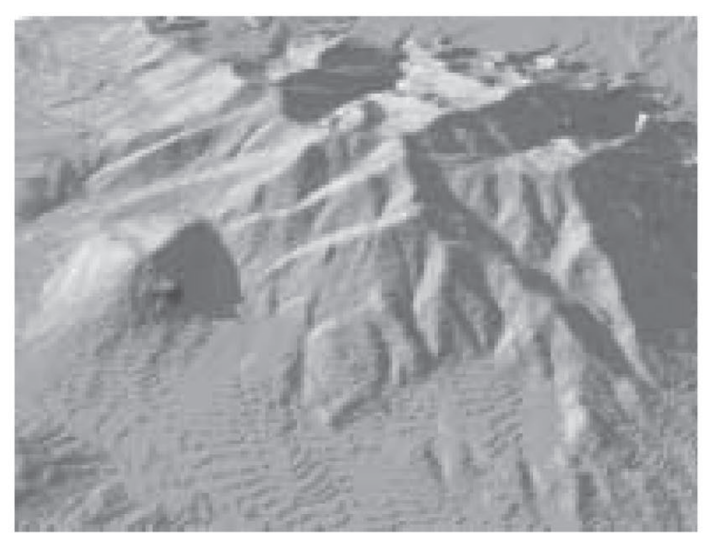

Figure 6. Description of questions T2 and T3, "Choose a 3D View." Only the correct 3D image (answer C) showing the perspective looking from the west for question T2 is included here. The other answers showed the perspective looking from the north (A), south (B), and east (D). The correct answer to T3 was choice D.

\section{Assumptions, Schemas, and Strategies Regarding Elevation and Slope}

Contour line spacing indicates elevation rather than slope. At the start of instruction, some students express the problematic assumption that the spacing of contour lines indicates elevation rather than slope. For example, students seem to think that areas with dense lines always represent mountains and that areas with few lines always represent lower elevations. This assumption holds true for a mountain in the middle of a plain but is not valid for features such as mesas or steep valleys. (The top of a mesa will have widely spread contour lines despite its higher elevation, while steep valleys have dense contour lines, but are lower in elevation than the surrounding terrain.) Three of the eight case-study students share this assumption in their pretest interviews, one of which is illustrated by Cara and her response to question C1 (Figure 4, "Describe Elevation Change").

Interviewer: What do you mean by smaller going into a bigger range?

Cara: Like the lines, the contour lines start small and then they widen. I kinda figured that you're traveling downward because it's more spread out.

She also expresses this view in explaining her answer to pretest question C2 (Figure 2, "Locate Lowest Elevation"): 
Table 2. Categories of assumptions exhibited by case study students on focal test questions $(n=8)$

\begin{tabular}{|c|c|c|c|c|c|c|c|c|c|c|c|c|}
\hline \multirow[b]{2}{*}{ Assumption } & \multicolumn{6}{|c|}{ Pretest } & \multicolumn{6}{|c|}{ Posttest } \\
\hline & I1 & $\mathrm{C} 1$ & $\mathrm{C} 2$ & $\mathrm{C} 3$ & $\mathrm{~T} 1$ & $\mathrm{~T} 2 / \mathrm{T} 3$ & $\mathrm{I} 1$ & $\mathrm{C} 1$ & $\mathrm{C} 2$ & $\mathrm{C} 3$ & & $\mathrm{~T} 2 / \mathrm{T} 3$ \\
\hline \multicolumn{13}{|l|}{ Elevation and slope } \\
\hline $\begin{array}{l}\text { All points on a contour line are the } \\
\text { same elevation }(\mathrm{n})\end{array}$ & & 2 & 3 & & 1 & & & 4 & 5 & & 1 & \\
\hline $\begin{array}{l}\text { Elevation change between contour } \\
\text { lines is constant }(\mathrm{n})\end{array}$ & & & 1 & 1 & & & & & 2 & 1 & & \\
\hline Numbers indicate elevation (n) & 4 & 7 & 6 & & 2 & & 4 & 8 & 8 & & 5 & \\
\hline Tick marks represent depressions (n) & 1 & & & & & & 1 & & & & & \\
\hline $\begin{array}{l}\text { Contour line spacing indicates } \\
\text { slope }(\text { close lines }=\text { steep })(n)\end{array}$ & 1 & 1 & 3 & 4 & 5 & 5 & 5 & 3 & 3 & 7 & 5 & 5 \\
\hline \multicolumn{13}{|l|}{$\begin{array}{l}\text { A few lines away means you are } \\
\text { closer to the number than several } \\
\text { lines }(t)\end{array}$} \\
\hline $\begin{array}{l}\text { Circles within each other that get } \\
\text { smaller indicate higher elevations }(t)\end{array}$ & 1 & 1 & 2 & & & & 2 & 1 & 3 & & & \\
\hline $\begin{array}{l}\text { Elevation is relative to the frame of } \\
\text { the page (higher on the page is } \\
\text { higher) (p) }\end{array}$ & & 1 & & & & & & & & & & \\
\hline $\begin{array}{l}\text { Contour line spacing indicates } \\
\text { elevation (less lines = lower } \\
\text { elevation) }(\mathrm{p})\end{array}$ & & 1 & 3 & 3 & & & & & 1 & 1 & & \\
\hline \multicolumn{13}{|l|}{ Shape of contour lines and terrain } \\
\hline $\begin{array}{l}\text { Shape of the contour lines mirrors } \\
\text { the shape of the features (n) }\end{array}$ & 5 & & & & & 2 & 5 & & & & & 5 \\
\hline Concentric circles represent hills $(\mathrm{t})$ & 5 & & & & & 2 & 7 & & & & & 5 \\
\hline $\begin{array}{l}\text { Adjective "round" in question } \\
\text { queues search for something } \\
\text { round on map }(t)\end{array}$ & 1 & & & & & & 1 & & & & & \\
\hline $\begin{array}{l}\text { Contour line spacing indicates } \\
\text { roughness (more lines = rougher } \\
\text { terrain) }(\mathrm{p})\end{array}$ & & & 1 & & & & & & & 2 & & \\
\hline $\begin{array}{l}\text { Jagged contour lines indicates } \\
\text { rougher terrain }(p)\end{array}$ & & & 0 & & & 2 & & & & & & 1 \\
\hline
\end{tabular}

Assumptions used as part of strategies

for 3D transformations

Rotation may be required to

51

54

63

Orientation equivalence of map and image assumed $(\mathrm{p})$

The letter after each assumption description signifies the degree of normativity: $\mathrm{n}=$ normative, $\mathrm{t}=$ transitional, and $\mathrm{p}=$ problematic. 
Cara: I put " $\mathrm{C}$," because it's more spread out compared to the rest of them; which has the lines, the contour lines, more closely together. Which I figured that if it's more closely together, it's steeper. And " $\mathrm{C}$ " is more low compared to the rest of them.

Interviewer: I'm not really clear here about what your thinking is. You said " $\mathrm{C}$ " because it's more spread out?

Cara: And the contour lines aren't close together.

Interviewer: "Spread-out contour lines" indicates what to you?

Cara: Flatter, plain. And zero elevation, you could say.

Interviewer: What indicated to you that it was at a lower elevation?

Cara: Well, if you look at the lines around "C," it's more spread out. If you look at distance, it's more wider, compared to "A."

Interviewer: And, that's how you got your elevation, if they're wider?

Cara: Right, if they're wider.

Zach also expresses this assumption in his pretest interview, but he later correctly explains in the posttest interview that the distance between contour lines indicates slope while the numbers indicate elevation:

The lines are so spaced apart ... the closeness is the drasticness of it and the further apart the more mellow the change is. (Zach)

Like Zach, by the end of instruction, most students have moved to the normative assumption that contour line spacing indicates slope rather than elevation. As Tony explains in his posttest interview:

Spacing doesn't necessarily mean it's going to be low or high ... These lines [pointing to the map] are spaced out. They could be at the top of a flat area, and [since] these lines aren't, they are at a lower elevation and they are sloping down. (Tony)

Bryan demonstrates similar improvement in his posttest interview, explaining that "the flattest topography is shown here. The more spaced out they are, the more flat it is."

Table 3. Overview of case-study participants (pseudonyms)

\begin{tabular}{lcccccc}
\hline $\begin{array}{l}\text { Case-study } \\
\text { student }\end{array}$ & $\begin{array}{c}\text { Pretest } \\
\text { topographic } \\
(\%)\end{array}$ & $\begin{array}{c}\text { Posttest } \\
\text { topographic } \\
(\%)\end{array}$ & $\begin{array}{c}\text { Pretest } \\
\text { self-rating } \\
(0-4)\end{array}$ & $\begin{array}{c}\text { Posttest } \\
\text { self-rating } \\
(0-4)\end{array}$ & $\begin{array}{c}\text { Cube } \\
\text { comparison } \\
(\%)\end{array}$ & $\begin{array}{c}\text { Surface } \\
\text { development } \\
(\%)\end{array}$ \\
\hline Shanda & 80 & 93 & 2 & 0 & 52 & 57 \\
Cara & 73 & 67 & 1 & 3 & 48 & 33 \\
Mandy & 87 & 100 & 1 & 2 & 43 & 93 \\
Katy & 47 & 80 & 1 & 2 & 24 & 13 \\
Moby & 87 & 100 & 2 & 3 & 95 & 93 \\
Bryan & 60 & 87 & 3 & 3 & 57 & 87 \\
Zach & 87 & 100 & 3 & 3 & 43 & 77 \\
Tony & 53 & 87 & 0 & 2 & 38 & 40 \\
Mean & 71 & 86 & $\mathbf{1 . 8 5}$ & $\mathbf{2 . 2 5}$ & $\mathbf{4 5}$ & 48 \\
\hline
\end{tabular}

The self-rating of topographic map skills uses the following scale: $0=$ none, $1=$ poor, $2=$ fair, $3=$ good, and $4=$ excellent. The cube comparison and surface development tests are standard tests of spatial ability (Ekstrom, French, Harman, \& Dermen, 1976). 
Elevation is relative to the frame of the page. One case-study student expresses the problematic assumption that elevation is relative to the frame of the page. In her pretest interview, Katy explains that areas closer to the top of a page are higher in elevation. During the interview, however, she notices that the numbers on contour lines may have been important:

Katy: I just looked ... at the [top?] it went up in elevation I think ... and it just looks as you go from " $X$ " to " $Y$ " that was what it is doing. But, oh, if you look at the numbers ... I didn't look at the numbers ... it looks like they are changing. I don't know if that has ... Does that have to do with elevation? It just looked like it was going higher up. I really didn't look at the numbers.

Interviewer: You didn't look at the number?

Katy: No.

Interviewer: And it looked like it was going higher up ... How could you tell?

Katy: Because " $X$ " is below " $Y$ ".

Interviewer: "Below" in what way do you mean?

Katy: Just the way it is positioned.

Interviewer: On the page?

Katy: Yeah.

Interviewer: $\mathrm{OK}$. " $\mathrm{X}$ " is below " $\mathrm{Y}$ " as it is positioned on the page.

Katy: Yeah, I guessed. I should have looked at the numbers.

Katy no longer expresses this problematic assumption at the end of instruction. It could possibly be related in some way to a misconception that all rivers flow south.

Elevation numbers and contour lines. As illustrated by Katy's responses above, not all students recognize that numbers represent elevation, but many students who report no prior experience with topographic maps apparently are able to deduce that numbers represent elevation during the pretest. In the pretest, seven of the eight casestudy students make the correct assumption that numbers on the contour lines represent elevation. As illustrated above, even immediately following the pretest, Katy realizes during her interview that the numbers might be important in answering this question. After 5 weeks of instruction, she still retains this more normative idea in her posttest interview:

Katy: I said you would be going down in elevation because at " $X$ " it has [the number] 7509 [written] a little bit before it and then as you go to " $Y$ " it has 7100. So just based on those I think it should be going down in elevation.

Interviewer: Could you have gotten that the first time you took the test?

Katy: If I had looked at the elevation ... If I had been more observant ...I don't know if the first [time] I looked at that or not. I might have just looked at "Y".

Interviewer: So it was probably something you could have done before even taking this class?

Katy: Yeah.

Katy now uses the numerical and contour line data from the map to determine elevation, rather than relying on her initial strategy where she considered elevation to be relative to the frame of the page. This revised strategy indicates an improved ability to decipher features of a mapped surface. 
Using their understanding of contour lines and elevation numbers, the students are able to compare different areas on the map. Shanda's explanation for her correct answer to posttest question C1 (Figure 4, "Describe Elevation Change") is similar to those of many case-study participants:

I looked at the two elevations that are closest to the letters. It says 7509 and then just a couple lines down the letter ' $X$ ' and then the letter ' $Y$ ' is 7100, which is the lower elevation. So, I figured you would be traveling down the elevation. (Shanda)

Zach expresses this assumption in both the pretest and posttest interviews, and correctly identifies the hill in question I1 (Figure 1, "Identify a Round Hill"). As Zach explains during the posttest interview:

Zach: The elevation at the top is really not that high.

Interviewer: How do you know it was not that high?

Zach: Just from the numbers [pointing at line 7023] ... compared to the other numbers and also it's round because you know the lines are in a circular formation.

It can be misleading to students when the assumption that only numbers represent elevations is applied wholesale without the knowledge of how additional data are embedded into the contour line symbols, which yields the fluctuation in local topography. Some students assume that the elevation of a point can be gauged by the nearest number label regardless of the number of intervening contour lines. Tony exhibits this on pretest question C2 (Figure 2, "Locate Lowest Elevation"), where all of the possible answers, except the correct answer, are near an elevation marker. Tony only looks at the elevation numbers closest to the letters and does not trace the lower contours back to the correct answer "C." Tony therefore does not consider the increments of elevations between contour lines. In his posttest interview, however, he has corrected his strategy using a similar, but differently labeled question:

Because I looked around the other letters, "B" happened to be the lowest elevation which is at 2200. "D" was around 24[00]. " $\mathrm{A}$ " was around 3000. " $\mathrm{B}$ " is what I believe to be correct now. (Tony posttest)

Bryan displays a similar approach to pretest question C3 (Figure 3, "Locate Flattest Topography"). He begins by arbitrarily selecting two lines with close proximity to both one another and the lettered choices. He calculates that the difference between $2,800 \mathrm{~m}$ and $2,400 \mathrm{~m}$ is $400 \mathrm{~m}$, which is smaller than the difference between $2,800 \mathrm{~m}$ and $2,252 \mathrm{~m}(548 \mathrm{~m})$. As a result, he concludes that because the difference of 400 is a smaller difference than 548, the example near the 400 meter calculation must represent flatter topography. His strategy, unfortunately, ignores the intervening contour lines without elevation numbers:

I don't know if I might've guessed on that or not [points to "B" and contour lines 2600 and 2200]. The difference between these two is only 400 in regards to steepness there so I mean I could have picked it because if it falls in between there .... Yeah, so the difference between to the two numbers are less between these numbers (2600 and 2200) is the least. (Bryan pretest) 
In the posttest, most students generally make the normative assumption that all points along a contour line are the same elevation. This is the second most frequently expressed assumption for question C2 (Figure 2, "Locate Lowest Elevation"). Casestudy students who express this assumption generally answer this question successfully if they also express the assumption that numbers represent elevation. The students who understand that all of the points on the line are the same elevation can trace along the line to find the same elevation elsewhere on the map. Shanda's response to posttest question C2 is representative:

I just looked at the different numbers and elevations nearest to the letters and followed the contour lines and just compared to see. (Shanda)

Cara explains in posttest question C1 (Figure 4, "Describe Elevation Change"):

Cara: " $X$ " to " $Y$ ", that's traveling downhill, because the elevation. It was "B." It is still traveling down in elevation, because the " $X$ " is on elevation 7509 and the " $Y$ " is on 7100 .

Interviewer: How did you know that the "Y" was on 7100? [there is no elevation number near "Y"]

Cara: Because you follow the contour line. You follow the line where " $Y$ " is at and it leads to 7100 .

As with the other questions, only a few students express this normative assumption for pretest question $\mathrm{C} 1$, but most students express a combination of two or more normative assumptions including this one in the posttest.

Hachure marks represent depressions. Hachure marks, which are used to identify contours around a depression, do not appear to be common knowledge. Prior to instruction, none of the case-study students' explanations for question I1 (Figure 1, "Identify a Round Hill") indicate that they use this assumption to help identify the hill. In the posttest interview, however, three of the students demonstrate clear understanding of hachure marks in their explanations:

Interviewer: Why might you think it [this feature] was not the opposite [of a hill], like a depression?

Cara: Because the way a depression is put, it is usually a circle with a line in the middle.

Interviewer: What kind of lines?

Cara: Vertical lines pointing inwards

Interviewer: Can you show me what you mean on the map?

Cara: Like on "W" ... that's a depression. [Cara correctly points to a depressed feature on the map.]

For the identification question about a feature with hachure marks (\#I2), 72\% of the class correctly identifies this feature as a depression in the pretest, as compared with $92 \%$ in the posttest. 


\section{Assumptions, Schemas, and Strategies Regarding Shape of Contours and Terrain}

Many students express a general assumption that the shape of the contour lines mirrors the shape of the feature. Sometimes this is non-productive, particularly when students assume that the horizontal shapes on the topographic map are indicative of the vertical profile of the topography. For example, Katy explains that jagged contour lines are characteristic of steeper, rougher terrain. While the jagged contours on that map certainly indicate that the terrain has many small topographic indentions or drainages, the indentations do not necessarily indicate an extreme degree of elevation or steepness.

Katy: You can tell 2000, 3000, and then 4000, 5000 ... It is going up in elevation. I guess it would be kind of mountainous terrain.

Interviewer: Why would you say it would be more mountainous?

Katy: Seems like it is getting steeper as it goes up. The contours ... the way they are spaced.

Interviewer: Is there a reason why this would be mountainous rather than a hill as in the first one?

Katy Just looking at the contour lines I think it would be mountainous.

Interviewer: Is there something about the contour lines?

Katy: The direction they are going in ... kind of how they are jagged and they are going up... and they are more jagged.

Interviewer: So, they are jagged, what does that mean?

Katy: To me it seems like it is a lot steeper and that would indicate a more mountainous area.

When students assume that the shapes of contour lines on a topographic map parallel the horizontal shapes of the topography, the assumption is more productive. For examples of this assumption, we focus on question I1 (Figure 1, "Identify a Round Hill"). Cara, who rated her ability as a "poor" topographic map-reader and scored within the 50th percentile in the pretest, was able to correctly answer question I1:

Cara: I chose "A" because the round hill ... because of the way it's shaped. Because its contour [lines] are round and it's more spread out compared to the other lines that are more close together.

Interviewer: Which are the contour lines? Would you explain to me which are the contour lines?

Cara: The lines that are making the circular motion that are close together.

Sometimes this assumption takes on a more rote form where students simply believe that concentric circles represent hills. This is obviously a useful connection even though it is potentially limiting (because circles within each other can also represent depressions if hachure marks are present). All of the students who express the assumption that concentric circles represent hills correctly answer question I1. Shanda's explanations exemplify these assumptions:

I think I said "A" [round hill] ... I thought that circles within each other got smaller when the elevation went up. (Shanda pretest)

I picked " $\mathrm{A}$ " Round Hill because the lines are in a rounded shape and going upwards. (Shanda posttest) 
Simply assuming that the shape of the contour lines represents the shape of the terrain is not always sufficient. Bryan, for example, tries to logically solve question I1 on the pretest by comparing contour lines of the feature within the box with those lines outside the area in question. As a result, he interprets this feature as a valley rather than a hill:

Interviewer: Could you tell me how you decided your answer, "valley"?

Bryan: I saw that this [points to contour line 7509 outside of the box] was at a higher elevation than this [line 7100 within the box] so I decided that it couldn't be a hill. Because it was decreasing, that's why I just came up with a valley; because it's a decrease in elevation.

In the posttest interview, however, Bryan explains:

Well, it's obviously a round hill because the lines ... these contour lines are all separated by all the same way as it's decreasing and it is symmetrical on both sides and it's very constant. It's not like a thin line, then a spaced out line, then a thin line. It's got to be a hill; it's all that it can be.

In the posttest interview, students express larger numbers of assumptions in conjunction with the idea that contour shape represents the shape of the topography than in the pretest interview. In fact, all of the students expressed at least three assumptions in their posttest interviews for question I1. For example, Moby provides a more sophisticated explanation in his posttest interview than in the pretest interview:

It just kind of seemed like a rounded hill. There's an area such as " $\mathrm{W}$ " right there and ... they are not real close to each other so it doesn't indicate a sharp rise. (Moby pretest)

Okay, I wrote "A" Round Hill ... Uh, generally because, well, it is not exactly a ridge because the contour lines follow the hill-like structure. There is not a sudden increase in frequency of the contour lines. It is not exactly a valley because of the number down here. The elevation it stays within and plus it actually increases. It goes from 7000 to 7023 so it actually increases. So it's not a valley. Uh, for depression there are no tic marks on either inside of the lines, therefore it's a rounded hill. (Moby posttest)

While the students bring useful knowledge to the class, they also make significant progress during the class.

\section{Assumptions, Schemas, and Strategies Regarding 3D Transformations}

To understand how students navigate between topographic maps and 3D representations, we interviewed students about question T1 (Figure 5, "Rotation of Azimuth and Perspective") and questions T2 and T3 (Figure 6, "Choose the 3D View"). Students describe several strategies, schemas, and assumptions with regard to solving these problems, including: (a) visualizing distinct topographic landmarks or the larger terrain, (b) feature recognition, (c) elevation comparison, and (d) direct mapping. Transformation questions prove the most challenging for the students and often result in guessing. 
Visualization. The most sophisticated strategy displayed by students involves visualizing the image as a composite of features and orienting the image based on one or more of the features. Two case-study students manage this on the pretest. Four of the case-study students exhibit this strategy on the posttest. Zach exemplifies this approach by using the small distinct hill and the larger mountain within the image for posttest questions T2 and T3:

Yeah, I just imagined myself standing on " $X$ " looking toward " $Y$ " and you'd see a little hill to your left and the mountainside behind it ending to your right ... It seemed to stand out more than the other features ... but I also used the mountainside. (Zach)

A more challenging application of this approach involves orienting the image using only ridges and valleys of the central mountain. Moby manages to successfully use this strategy in the pretest interview:

Well, I had to find a looking element such as this ridge where a nice little arc goes this way and back this way.

On question T1 (Figure 5, "Rotation of Azimuth and Perspective"), Moby uses a similar approach, imagining himself on the map and what he would see in each direction. He then locates the point on the topographic map that would have the same views in each direction. Tony also provides a good example of this approach in posttest question T1:

I noticed that this one was actually rotated. This little slope right here [pointing to image], is what these contour lines [pointing to map] are representing, how they're closer together then other areas. I noticed that this slope right here [pointing to image], was ... these lines right here [pointing to map], and the top of this mountain right here was this cliff/ridge right here which it descended quickly ... (Tony)

These most successful students are able to visualize the terrain on the topographic map and then compare it with the land-surface perspectives through their holistic visualization of the topographic map and the terrain it represents.

Feature recognition. Another successful strategy involves identifying the features at each of the points on the topographic map and choosing the one that matches the features at the point in question on the land-surface perspective. This strategy does not require the students to visualize large sections of the topographic map as a whole, but rather to use logic and deduction based on a smaller number of features of the topographic map in order to match it to the land-surface perspective. For question $\mathrm{T} 1$, one case-study student follows this strategy successfully on the pretest, two others use this strategy successfully in the posttest, and one uses this strategy unsuccessfully in the posttest. As Zach successfully explains in the pretest interview:

I couldn't decide if it was " $\mathrm{B}$ " or " $\mathrm{D}$ " because they're both close ... both show a steep grade. But then what I did is just flip the map around and " $\mathrm{A}$ " matches really well with ... like ... when you kinda see the slope coming this way ... I knew it wasn't " $A$ " so I figured "A was somewhere around here [pointing at the lowest middle position on the image] ... I kinda matched up the map. You can tell since there's since there's so many lines bunched up there. 
This strategy involves important components of the more advanced visualization strategy, but does not require students to create larger integrated images of the topographic map.

A similar, but less successful, set of approaches for questions T2 and T3 (Figure 6, "Choose the 3D View") involves focusing on discreet individual features of the central mountain and orienting on the general shape using the elevation numbers, the proximity of the lines, or the shape of the lines. Students using this approach seem less able to visualize the features and instead try to work out the question logically. Katy and Zach focus primarily on the shape of the lines in the pretest (Katy unsuccessfully and Zach successfully). Katy unsuccessfully focuses on the proximity of the lines in the posttest. She observes the spacing between the lines and recognizes the steeper terrain in the middle of the map. Using this approach, Katy narrows her choice down to two possible images. As Katy explains, "I am saying left to right. So I just kind of looked at ' $\mathrm{X}$ ' and ' $\mathrm{Y}^{\prime}$, and ' $\mathrm{D}$ ' is kind of going left to right."

Elevation comparison. Another less successful approach involves focusing primarily on elevations instead of focusing on the shape of the terrain. For question T1 (Figure 5, "Rotation of Azimuth and Perspective"), one student successfully and two students unsuccessfully pursue this strategy in the pretest and determine that the target point on the land-surface perspective is at a middle elevation and then search for points on the topographic map with middle elevations. There are two such labeled points at middle elevations on the topographic map for question T1, but only one of the three students choose correctly between the two points. Two students use this strategy successfully in the posttest, which suggests that they are supplementing this strategy with some use of the contour lines in terms of shapes and patterns. As Mandy explains in the pretest interview:

Like I tried to figure out which way this applies to at first and I saw that there is a higher elevation here and here [she pointed to the top left and right areas of the top map]. It goes down a little and up again. So I tried to figure out that this point and this point are probably the two highest points in the area right here:

This strategy involves some important symbolic interpretation, but ignores important information about slope and shape from the contour lines.

Cara successfully chooses the correct answer for pretest questions T2 and T3 (Figure 6, "Choose the 3D View") using the elevation numbers. Starting at the lower left corner and moving from lower to higher elevation numbers, Cara goes back and forth from map to picture:

I had to look at all of them. Look at all the pictures to see whether it matched up, "X" approaching "Y". Then I looked at the topographic map. Because it was widespread at the beginning on the " $\mathrm{X}$ " side and towards the " $\mathrm{C}$," the contour lines are closely together. I first had to match up the pictures what started off wide or flat and then work my way up. (Cara) 
Direct mapping. An unsuccessful strategy of last resort involves assuming a direct proportional geometric mapping between the topographic map and the land-surface perspective. Using this strategy, the students assume that area and the borders represented on the topographic map and the land-surface perspective are identical. Students assume, for example, that a the target location on a topographic map is twothirds of the way to the left and one-half of the way up because those are the same proportionate locations of the point on the land-surface perspective.

Three case-study students employ this strategy unsuccessfully on the pretest and one student employs it unsuccessfully in the posttest. As Katy explains on the pretest interview, " $\mathrm{X}^{\prime}$ was in the same position it seemed as ' $\mathrm{A}$ ' [was] in the other picture." Here, position appeared to be a function of their location relative to the frames of the image and map. This strategy does not result in the correct answer on this question and would generally be of no practical use in the field.

For pretest Questions T2 and T3, Bryan answers the question with the direct mapping strategy. He describes a mountain as "more" or "less dense," and when asked for further explanation on his terminology and problem-solving method he says:

These lines obviously represent a mountain, so these lines over here represent a plain or end of a mountain ... The mountain doesn't start until it's about an inch in [from the edge of the map] and this one [points to wrong answer] is the best one where it starts an inch in [from the edge of the map]. (Bryan)

This strategy is successful for Bryan for this particular question, but for most problems this strategy of direct mapping would be hit-or-miss.

\section{Discussion and Conclusions}

Even prior to instruction, students demonstrate success in making inferences about the symbolic information in the topographic maps. This initial success should not be misinterpreted, however, as an integrated level of expert understanding. Only in the posttest interviews do most students express explanations integrating the assumptions, schemas, and strategies in a manner more similar to expert behavior. In the posttest interviews, for example, students are able to interconnect the ideas that the lines and numbers on the maps refer to elevations, that all points on a line are the same elevation, and that the shapes of the contour lines are related to the shapes of the landscape features. Although many students on the pretest extrapolate the relationship between contour line spacing and slope, at least at a logical level, it is not until after instruction that students become more consistent in the way they employ strategies to solve problems conceptually. In the posttest interviews, students begin to distinguish intricate map features, such as valleys and mesas, with greater precision. Students also demonstrate familiarity with basic map symbols, such as the hachure marks, which were not intuitive symbols for them on the pretest.

The posttest interviews and students' self-ratings also demonstrate that students have an increased confidence in their map reading abilities (pre-self-rating, $M=$ 
1.60, $S D=0.91$; post-self-rating, $M=2.46, S D=0.66$; scale $0=$ none, $1=$ poor, $2=$ fair, 3 $=$ good, and $4=$ excellent). This finding is not surprising, but is encouraging, because the students are now relying on their newly acquired knowledge to provide sound reasoning to their answers rather than relying on intuition and "test-savvy" to solve problems.

\section{Challenges: Visual-spatial ability, misconceptions, and map complexity}

Although the students make significant progress during the curriculum, the students continue to face challenges with topographic maps after instruction, particularly on the transformation questions. We hypothesize three main sources of difficulty for students in terms of these challenging questions.

First, varying spatial skills among the students may explain part of the difficulty. The ability to visualize a 3D landscape from a 2D map involves more than understanding the symbols. As Boardman (1989) explains, "pupils learn to perceive contours but have to imagine slope, and then put slopes together mentally in attempting to visualize the terrain." Supporting this explanation, some students in the interviews demonstrate higher ability than others in rotating perspectives on the maps. These students may have stronger spatial skills. This would suggest the need for specific curricula (e.g., Piburn et al., 2005 ; Reynolds, Piburn, \& Johnson, 2002) to help underperforming students with their spatial-visualization skills.

Second, in addition to highlighting possible spatial-visualization issues, the posttest interviews highlight some persistent basic misconceptions and incorrect schemas. For instance, some students continue to assume that closely spaced contour lines represent higher elevation and that widely spaced contour lines indicate lower elevations. Similarly, some students continue to assume that wavy contour lines indicate steeper or more extreme landscapes. Another persistent misconception involves the direct-mapping technique. This is the assumption that the map and the image are similarly oriented and dimensioned so that a specific point on the map can be calculated based on the same ratio of proportions on the image. We see many of the students employ this strategy in the pretest and some students still revert back to this strategy in the posttest. This suggests that students' preconceptions are robust and difficult to change, as has been demonstrated in other studies regarding conceptual change (e.g., Chinn \& Brewer, 1993).

Finally, synthesizing multiple normative assumptions to answer more complex questions apparently remains very challenging for students in the posttest. The sheer number of features and details involved in the transformation questions appears overwhelming. The maps for the transformation question are more representative of maps that students would probably encounter in real-world applications. Whereas the identification and comparison questions involve the analysis and interpretation of a relatively small area or number of features, the transformation questions involve a larger number of various landforms and would be a more typical and familiar task for the expert geologist. Any one of these landforms on a transformation question map may be no more complex than the landforms on the identifi- 
cation and comparison questions, but the increased number of features and details may increase cognitive load beyond the capacity of a novice student to maintain a holistic image of the terrain represented in sufficient detail to achieve the task. This would be in keeping with the findings of Eley (1988) that subjects encode mental representations of land surface shape in a "particular" rather than "general" fashion. As discussed, Eley found that the participants conceptualized the image better as a collection of separable elements than a single connected entity. Cognitive overload would potentially result from students' conceptualization of the image as a collection of a larger number of separable elements rather than as a holistic generalized image. These students need to be supported in developing more powerful schemas so that they successfully can "chunk" larger sets of features to handle maps involving greater complexity.

\section{Implications}

This study highlights some important considerations for the construction of curricular activities and assessments. One clear implication of the study is that students know a great deal more about topographic maps when they first enter an introductory physical geology course than we might think, or at least that they can figure out some of the basic principles on the spot. The geoscience education community needs to take this prior knowledge into account when designing curriculum for their courses. Specifically, this points to the importance of assessing students' prior knowledge to instruction when measuring the success of curricular interventions. If instructors only administer posttests, high student test scores might suggest high curricular efficacy even though students might have scored well on the same questions on a pretest despite their claims of minimal prior experience.

A second implication involves the importance of determining what students should know as a result of instruction. Clearly, students quickly manage many aspects of interpreting the symbolic information on topographic maps. The more important question for instructors involves determining what types of complex tasks students should know and master. If only basic skills are important, then minimal intervention is required. However, if we decide that students should be able to negotiate complex transformation questions or interact with complex landforms, then we need to design additional curriculum to support students in developing the appropriate abilities and schemas necessary for success on those tasks. This may also potentially involve committing more time in the curriculum for these activities. The transformation questions proved to be the most challenging for students in both semesters. A large percentage of students under-perform on these questions in the posttest. It is possible that transformation tasks involving both rotation and visualization are not actually critical for these non-science majors, in which case the curriculum does not need to increase emphasis in these areas. When they are out in the field, geology students must employ additional skills to use magnetic and Brunton compasses to aid them in the process of orientation. While the tools may help in a general sense, the issue of rotation in addition to visualization remains a very com- 
plex task requiring focused instruction and practice. Ishikawa and Kastens (2005) also emphasize that "mental-rotation ability or perspective-taking ability could be relevant to those geologic tasks that involve envisioning what a geologic structure might look like if seen from another position." Physical geology instructors and curriculum developers need to determine the most appropriate goals for their target audience and then make curriculum and assessment choices based on those decisions.

A third implication relates to the second. Once we decide what students should know and be able to do, we need to develop our assessment questions to measure those specific skills. Essentially, our assessments must measure what we intend to teach. For example, transformation questions, comparison questions, and identification questions appear to measure different skills. Once we decide what we want students to know and be able to do, we need to develop questions to measure those skills. We can create more complex test questions by increasing cognitive load in terms of number of elements or increased spatial demands, but are these the tasks that we consider important for students to master beyond the mental challenge for its own sake?

Finally, a fourth implication is that assessments should not be designed to reward non-normative strategies such as direct mapping. To avoid direct-mapping, for example, the boundaries of topographic maps and the land-surface perspectives should not exactly coincide (i.e., the topographic map might cover a larger area than does the 3D land-surface perspective model, therefore forcing the student to locate a specific area that contains that excerpted feature). We need to continue research into the strategies that students use on our assessments to make sure that students are rewarded for normative practices and not for artificial test-taking strategies; true learning has not occurred if students state the correct answer for the wrong reason.

\section{Closing Thoughts}

The insights from this study into students' understanding of topographic maps will ideally facilitate further evaluation and revision of geology curricular goals, activities, and assessment. In fact, based on this study, we have made several revisions to our own course curriculum and tests to ensure that our activities and assessments align more closely with one another. This study highlights the fact that even students who claim never to have worked with topographic maps can often perform quite impressively on a pretest by making useful assumptions about symbolic topographic information. We need to refocus our curricula to take advantage of these initially productive skills and assumptions while helping students overcome their less productive assumptions. For those who choose to pursue a career in the geosciences, we need to attend to the specific more advanced problems they may encounter while learning how to map geologic features in the field. Many interesting geomorphologic problems have been solved by landscape analysis, such as the Channeled Scablands of Washington State and the interpretation of the Mid-Atlan- 
tic Ridge as an expression of seafloor spreading (which was critical in the advancement of the theory of plate tectonics). We owe much of our current understanding of Earth systems to geoscientists' visualization of topographic information.

This study also highlights important questions for ongoing research. Further analysis of the strategies, schemas, and assumptions that college students bring to their geoscience courses, along with detailed analyses of how to facilitate the transformation of those strategies, schemas, and assumptions in the classroom, will ideally facilitate the creation of better curricula and assessments. These enhanced curricula, in turn, will better prepare students for their future careers and everyday lives. In particular, this study suggests further investigation of curricula to support the development of spatial-visualization skills and schemas appropriate for parsing complex landscapes with multiple features.

\section{References}

Boardman, D. (1989). The development of graphicacy: Children's understanding of maps. Geography, 74(4), 321-331.

Brewer, W., \& Nakamura, G. (1984). The nature and functions of schemas. In R. S. Wyer \& T. K. Skull (Eds.), Handbook of social cognition (vol. 1). Hillsdale, NJ: Lawrence Erlbaum.

Carlson, L. A. (1999). Selecting a reference frame. Spatial Cognition and Computation, 1(4), 365-379.

Carter, G., Patrick, M., Wiebe, E. N., Park, J. C., \& Butler, S. M. (April, 2005). Middle grade students' interpretation of topographic maps. Paper presented at the proceedings of NARST 2005, Dallas, TX.

Cave, K., \& Wolfe, J. (1990). Modeling the role of parallel processing in visual search. Cognitive Psychology, 22, 225-271.

Chang, K.-T., Lenzen, T., \& Antes, J. (1985). The effect of experience on reading topographic relief information: Analyses of performance and eye movements. The Cartographic Journal, 22, 88-94.

Chase, W., \& Simon, H. (1973). The mind's eye in chess. In W. G. Chase (Ed.), Visual information processing. New York: Academic Press.

Chinn, C. A., \& Brewer, W. F. (1993). The role of anomalous data in knowledge acquisition: A theoretical framework for science instruction. Review of Educational Research, 63(1), 1-49.

de Groot, A. (1978). Thought and choice in chess. The Hague, Mouton. (Original work published 1946)

Duncan, J., \& Humphreys, G. (1992). Beyond the search surface: Visual search and attentional engagement. Journal of Experimental Psychology: Human Perception and Performance, 18, 578-588.

Eastman, J. R. (1985). Graphic organization and memory structures for map learning. Cartographica, 22(1), 1-20.

Ekstrom, R. B., French, J. W., Harman, H. H., \& Dermen, D. (1976). Manual for kit of factor referenced cognitive tests. Princeton, NJ: Educational Testing Service.

Eley, M. G. (1981). Imagery processing in the verification of topographical cross-sections. Educational Psychology, 1(1), 39-48. 
Eley, M. G. (1987). Colour-layering and the performance of the topographic map user. Ergonomics, 30(4), 655-663.

Eley, M. G. (1988). Determining the shapes of landsurfaces from topographic maps. Ergonomics, 31(3), 355-376.

Eley, M. G. (1991). Selective encoding in the interpretation of topographic maps. Applied Cognitive Psychology, 5, 403-422.

Eley, M. G. (1993). The differential susceptibility of topographic map interpretation to influence from training. Applied Cognitive Psychology, 7, 23-41.

Ghuman, P. A. S., \& Davis, R. (1981). An assessment of adolescent comprehension of some geographical concepts using Peel's theoretical framework. Educational Review, 33(3), 231-240.

Gilhooly, K. J., Wood, M., Kinnear, P. R., \& Green, C. (1988). Skill in map reading and memory for maps. The Quarterly Journal of Experimental Psychology, 40A(1), 87-107.

Gobert, J. (1994). Expertise in the comprehension of architectural plans: Contribution of representation and domain knowledge. Unpublished dissertation, University of Toronto, Toronto, Ontario.

Gobert, J. (2005). The effects of different learning tasks on model-building in plate tectonics: Diagramming versus explaining. Journal of Geoscience Education, 53(4), 444-455.

Gobert, J. (2005). Leveraging technology and cognitive theory on visualization to promote students' science learning and literacy. In J. Gilbert (Ed.), Visualization in science education (pp. 73-90). Dordrecht, The Netherlands: Springer-Verlag.

Ishikawa, T., \& Kastens, K. A. (2005). Why some students have trouble with maps and other spatial representations. Journal of Geoscience Education, 53(2), 184-197.

Just, M. A., \& Carpenter, P. A. (1985). Cognitive coordinate systems: Account of mental rotation and individual differences in spatial ability. Psychological Review, 92(2), 137-172.

Kinnear, P. R., \& Wood, M. (1987). Memory for topographic contour maps. British Journal of Psychology, 78, 395-402.

Lanca, M. (1998). Three dimensional representation of contour maps. Contemporary Educational Psychology, 23, 22-41

Larkin, J., \& Simon, H. (1987). Why a diagram is (sometimes) worth ten thousand words. Cognitive Science, 11, 65-100.

Lloyd, R. (1997). Visual search processes used in map reading. Cartographica, 34(1), 11-31.

Logan, G. D., \& Sadler, D. D. (1996). A computational analysis of the apprehension of spatial relations. In P. Bloom, M. A. Peterson, L. Nadel, \& M. F. Garrett (Eds.), Language and space: Language, speech, and communication (pp. 493-529). Cambridge, MA: The MIT Press.

Lowe, R. K. (1993). Constructing a mental representation from an abstract technical diagram. Learning and Instruction, 3, 157-179.

Mayer, R. E., \& Gallini, J. K. (1990). When is an illustration worth ten thousand words? Journal of Educational Psychology, 82(4), 715-726.

Mou, W., \& McNamara, T. (2002). Intrinsic frames of reference in spatial memory. Journal of Experimental Psychology: Learning, Memory, and Cognition, 28(1), 162-170.

Neisser, U. (1967). Cognitive psychology. New York: Appleton-Century-Crofts.

Piburn, M. D., Reynolds, S. J., McAuliffe, C. M., Leedy D. E., Birk, J. P., \& Johnson, J. K. (2005). The role of visualization in learning from computer-based images. International Journal of Science Education, 27(5), 513-527. 
Rieber, L. P. (1995). A historical review of visualization in human cognition. Educational Teaching, Research and Development, 43, 45-56.

Reynolds, S., Piburn, M. D., \& Johnson, J. K. (2002). Interactive 3D visualizations of geology creation, use, and assessment. Paper presented at annual meeting of Geological Society of America, Denver, CO.

Rumelhart, D., \& Norman, D. (1975). The active structural network. In D. Norman, D. Rumelhart, \& L. R. Group (Eds.), Explorations in cognition. San Francisco, CA: W. H. Freeman.

Schank, R., \& Abelson, R. (1977). Scripts, plans, goals, and understanding. Hillsdale, NJ: Lawrence Erlbaum.

Schofield, N. J., \& Kirby, J. R. (1994). Position location on topographical maps: Effects of task factors, training, and strategies. Cognition and Instruction, 12(1), 35-60.

Shelton, A. L., \& McNamara, T. P. (2001). Systems of spatial reference in human memory. Cognitive Psychology, 43, 274-310.

Treisman, A. (1991). Search, similarity, and integration of features between and within dimensions. Journal of Experimental Psychology: Human Perception and Performance, 17, 652-676 